\title{
The effect of health education programs for parents about breakfast on students' breakfast and their academic achievement in the north of Jordan
}

\author{
Mariam M.Kawafheh ${ }^{1 *}$, Falastine R. Hamdan ${ }^{2}$, Shalabia El-Sayed Abozeid ${ }^{3}$, Hani Nawafleh ${ }^{4}$ \\ ${ }^{I}$ Irbid National University, Jordan \\ ${ }^{2}$ Al-Balqa University, Jordan \\ ${ }^{3}$ Associate Professor Al Hussein Bin Talal University, Jordan \\ ${ }^{4}$ Associate Prof.Al-Hussein Bin Talal University, Jordan \\ *Corresponding author E-mail: mariamsltn204@gmail.com
}

\begin{abstract}
Background: Breakfast is often said to be the most important meal of the day, there is a significant evidence of positive academic effects due to breakfast consumption.

Objectives: The purpose of this study is to examine whether the health education intervention about breakfast for parents leads to improvement in students' breakfast intake and their academic achievements, it also aims at investigating the effect of students' gender and class on their performance.

Methods: The sample of the study was selected by random sampling technique. It consisted of (234) students, (115) male and (119) female students at Fatima Bent Al Yaman school for girls and Khaled Ben Al Walid school for boys in Irbid the first Directorate of Education in the first semester 2013/2014 and was distributed into four sections, which were selected purposefully two female sections and two male sections.

Results: findings of the study indicated that there were statistically significant differences in the post- tests between the control and the experimental groups in favor of the experimental group which their parents were exposed to health education intervention about breakfast, and there was no statistically significant difference in the students' achievement due to gender or to the interaction between gender and group.
\end{abstract}

Conclusion: breakfast has a positive effect on students' academic performance.

Keywords: Academic Achievement, Health Education Programs, School Children.

\section{Introduction}

There are at least a few ways by which breakfast can affect academic performance. First, a nutritionally balanced meal provided early in the day can improve student health when the meal received otherwise is inferior. Some research suggests greater levels of health and nutrient intake can benefit student cognitive performance, improving academic performance and learning efficacy (Kleinman et al., 2002; Gleason and Suitor, 2003; Florence et al., 2008, Kawafha, 2013). Second, the incentive of meal provision-in addition to improved health and nutrition-may reduce tardiness and have positive effects on overall student attendance rates (Kleinman et al., 2002). Third, school provided meals are likely to reduce student household food expenditure. To the extent that positive income shocks are associated with increases in student performance (Dahl \& Lochner, 2010), breakfast may improve student outcomes through a household income effect. Fourth, because breakfast is administered after class begins, reallocating instruction time for the program means breakfast can potentially have a negative impact on students' academic outcomes. To the extent that later school starting times translate into more sleep or rest time, they too can affect student outcomes. Finally, breakfast integrates students across income strata within a classroom.
The benefits of breakfast: health \& academics:

Breakfast is often said to be the most important meal of the day. Research shows that students benefit from eating breakfast in two primary ways. First, students' overall dietary health is positively affected by breakfast consumption, particularly meals provided through the School Breakfast Program (Gleason, \& Suitor, 2001) Second, there is a significant evidence of positive academic effects due to breakfast consumption (Kawafha, 2013). Schools experience improvements in standardized test scores and improvements in school attendance in addition to other outcomes that create positive learning environments. Serving school breakfast to all students helps ensure that they are well nourished and ready to learn. Studies of school breakfast programs have found that students who eat breakfast at school show improved academic achievement, especially in vocabulary, math and standardized tests, have better records, are less likely to be tardy and exhibit fewer behavioral and psychological problems. Children who regularly eat breakfast also have a better quality of nutrient intake and are less likely to be overweight or obese.

\subsection{Significance of the study}

Research demonstrates that eating breakfast truly can be a critical factor in improving student health and learning. Because many 
students do not take their breakfast in the morning, having breakfast can be a way for students to get nourishment and attain healthy body weight. Research also suggests that eating a nutritious breakfast can have a number of positive impacts on student learning, including: having breakfast is correlated with better grades and lower rates of absenteeism and tardiness. (Murphy\& Pagano, 2001)

Parents therefore have an opportunity to improve student health and academic achievement through paying more attention on the importance of breakfast to their kids.

\section{Statement of the problem:}

In an educational world filled with failing schools and apathetic students, state boards of education have searched for answers on how to increase test scores and create school systems where all students receive the best education possible. Amongst the plethora of possible solutions, perhaps they should look first at the nutritional substance of what our school-aged children are eating each day as they struggle through a day of learning. There is a correlation between nutrition and cognition as well as psychosocial behavior; this relationship has been highly under-researched, but there exists many studies that look at the nutritional benefits of many proteins, vitamins, and food substances as they affect learning and brain function. Parents have the potential to play a vital role in preparing and sustaining students' potential learning abilities and benefitting their social behaviors by supplying nutritious breakfasts and lunches during school days.

\subsection{Purpose of the study}

To examine whether the health education intervention about breakfast for parents leads to improvement in students' breakfast intake and their academic achievements, it also aims at investigating the effect of students' gender and class on their performance.

\subsection{Questions of the study}

The central questions that will guide this inquiry are the following:

1) Are there any statistically significant differences in students achievement due to the health education intervention about breakfast for parents?

2) Are there any statistically significant differences in students achievement due to their class (third grade, fourth grade)

3) Are there any statistically significant differences in students achievement due to their gender (male, female)?

4) Are there any statistically significant differences in students achievement due to the interaction between group and gender?

\subsection{Limitations of the study}

This study is limited to all male and female students at Fatima bent Al Yaman School for girls and Khaled ben Al Walid School for boys in Irbid the first Directorate of Education in Irbid in Jordan.

\section{Literature review}

PR Newswire (2013) introduced a study entitled "Healthy Students Are Better Students: New Report Illustrates "The Wellness Impact" Of Good Nutrition and Physical Activity on Improving Academic Achievement" As schools prepare for standardized testing this spring, school leaders, teachers and parents are focused on ensuring students are prepared to do their best. Research shows that regular access to better nutrition starting with breakfast coupled with increased opportunities for physical activity may help students reach their potential throughout the school year, which may lead to better performance at testing time and beyond.

Leos et al (2013) conducted a study entitled " Not just for poor kids: The impact of universal free school breakfast on meal participation and student outcomes". The researchers estimate the im- pact of New York City's shift to universal free school breakfast. Breakfast participation increased modestly for all school meal eligibility groups. Increases for those previously free-meal-eligible suggest a non-price mechanism. A concurrent lunch price increase did not affect full price students' participation. The researchers claimed that they find limited impact of the policy change on educational outcomes.

Acham et al (2012) conducted a study entitled "Breakfast, midday meals and academic achievement in rural primary schools in Uganda: implications for education and school health policy." In their study they stated that underachievement in schools is a global problem and is especially prevalent in developing countries. Indicators of educational performance show that Uganda has done remarkably well on education access-related targets since the introduction of universal primary education in 1997. However, educational outcomes remain disappointing. The absence of school feeding schemes, one of the leading causes of scholastic underachievement, has not been given attention by the Ugandan authorities. Instead, as a national policy, parents are expected to provide meals even though many, especially in the rural areas, cannot afford to provide even the minimal daily bowl of maize porridge. To assess and demonstrate the effect of breakfast and midday meal consumption on academic achievement of schoolchildren, the researchers assessed household characteristics, feeding patterns and academic achievement of 645 schoolchildren (aged 9_15 years) in Kumi district, eastern Uganda, in 2006_2007, using a modified cluster sampling design which involved only grade 1 schools (34 in total) and pupils of grade four. Household questionnaires and school records were used to collect information on socio-demographic factors, feeding patterns and school attendance. Academic achievement was assessed using UN standardized techniques, specifically designed for this study.

Underachievement (the proportion below a score of 120.0 points) was high (68.4\%); in addition, significantly higher achievement and better feeding patterns were observed among children from the less poor households. Achievement was significantly associated with consumption of breakfast and a midday meal, particularly for boys, and a greater likelihood of scoring well was observed for better nourished children.

The researchers observed that underachievement was relatively high; inadequate patterns of meal consumption, particularly for the most poor, significantly higher scores among children from 'less poor' households and a significant association between academic achievement and breakfast and midday meal consumption.

Basch, C. (2011) conducted a study entitled "Breakfast and the Achievement Gap among Urban Minority Youth" the aim of his study is to outline the prevalence and disparities of breakfast consumption among school-aged urban minority youth, causal pathways through which skipping breakfast adversely affects academic achievement, and proven or promising approaches for schools to increase breakfast consumption. On any given day a substantial proportion of American youth do not eat breakfast. On an average day, less than half $(\sim 46 \%)$ of children participating in free or reduced-price lunch also participated in the School Breakfast Program for which they were also eligible. In a large study of 9 -year-olds, $77 \%$ of White girls and $57 \%$ of Black girls consumed breakfast on all 3 days assessed; by age 19, the respective rates were $32 \%$ and $22 \%$. Neuroscience research has identified the processes by which dietary behavior influences neuronal activity and synaptic plasticity, both of which influence cognitive functions. Participation in School Breakfast Programs has also been associated with reduced absenteeism. Universal School Breakfast Programs and allowing youth to eat breakfast in the classroom (vs cafeteria) are approaches that have been shown to increase participation. The researcher conclude that skipping breakfast is highly and disproportionately prevalent among school-aged urban minority youth, has a negative impact on academic achievement by adversely affecting cognition and absenteeism, and effective practices are available for schools to address this problem. Despite wide availability, the majority of American 
youth do not participate in School Breakfast Programs. Highquality universal breakfast programs that allow students to eat breakfast in the classroom are especially needed for youth who are not likely to get good nutrition the rest of the day.

$\mathrm{Ni}$ et al (2010) conducted a study entitled "Effects of a free school breakfast program on school attendance, achievement, psychosocial function, and nutrition: a stepped wedge cluster randomized trial" they claimed that approximately 55,000 children in New Zealand do not eat breakfast on any given day. Regular breakfast skipping has been associated with poor diets, higher body mass index, and adverse effects on children's behavior and academic performance. Research suggests that regular breakfast consumption can improve academic performance, nutrition and behavior. This paper describes the protocol for a stepped wedge cluster randomized trial of a free school breakfast program. The aim of the trial is to determine the effects of the breakfast intervention on school attendance, achievement, psychosocial function, dietary habits and food security. Sixteen primary schools in the North Island of New Zealand will be randomized in a sequential stepped wedge design to a free before-school breakfast program consisting of non-sugar coated breakfast cereal, milk products, and/or toast and spreads. Four hundred children aged 5-13 years (approximately 25 per school) will be recruited. Data collection will be undertaken once each school term over the 2010 school year (February to December). The primary trial outcome is school attendance, defined as the proportion of students achieving an attendance rate of $95 \%$ or higher. Secondary outcomes are academic achievement (literacy, numeracy, self-reported grades), sense of belonging at school, psychosocial function, dietary habits, and food security. A concurrent process evaluation seeks information on parents', schools' and providers' perspectives of the breakfast program. This randomized controlled trial will provide robust evidence of the effects of a school breakfast program on students' attendance, achievement and nutrition. Furthermore the study provides an excellent example of the feasibility and value of the stepped wedge trial design in evaluating pragmatic public health intervention programs.

Cheng et al (2008) conducted a study entitled "Children's Perceptions of Parental Attitude Affecting Breakfast Skipping in Primary Sixth-Grade Students" they said that breakfast skipping is an international public health concern. This study investigated the prevalence of breakfast skipping among primary sixthgrade students in Hong Kong and the impact of students' perceptions of parental attitudes on breakfast skipping. Methods: A total of 426 students aged 10-14 years in 4 local schools participated in this cross-sectional study and completed a questionnaire adapted from an earlier study in Queensland. Breakfast skipping was defined as having missed any food or beverage (except water) between waking and the commencement of morning school classes at least 1 school day during the past week. Multiple logistic regression analyses were performed to explore the potential risk factors of breakfast skipping. Results: Of the 426 students, 130 (30.5\%, 95\% confidence interval [CI]: 26.1-34.9) reported skipping breakfast for at least 1 day in a school week. Multiple logistic regression analyses showed that breakfast skipping was associated with lack of perceived parental emphasis on breakfast (odds ratio $[\mathrm{OR}]=3.67,95 \% \mathrm{CI}: 1.75-7.68)$ and not believing that breakfast consumption could help concentration in class (OR $=3.82$, 95\% CI: 1.86-7.87). Conclusions: This study suggested that breakfast consumption habits could stem from the students' beliefs and perceptions. Thus, working with students, parents, and schools to build up positive knowledge and beliefs about breakfast consumption might be useful.

Herrero, L. \& Fillat, B. (2006) conducted a study entitled "A study on breakfast and school performance in a group of adolescents" the purpose of this study is to know the relationship between breakfast, from a qualitative perspective, and school performance. The study was performed in 141 students (70 males and 71 females) with ages ranging 12-13 years, of 1st grade of Mandatory Secondary Education (ESO) from an institute of Saragossa, by means of recalling the breakfast of the day before. Breakfast quality has been assessed according to criteria of the Kid study: good quality: contains at least one food from each one of dairy, cereals, or fruit groups. Improvable quality: lacks one of the groups. Insufficient quality: lacks two groups. Poor quality: does not have breakfast. We considered that quality was improved only when a mid-morning snack with a different food from those taken with breakfast was added. Average mark at the end of the school year has been the criterion used to assess school performance. Statistical analysis of data gathered for the present study has been done with SPSS software. This analysis comprises descriptive and inferential statistics. For analysis of global significance between the differences the Analysis of Variance method has been applied, followed by post hoe tests with Bonferroni's and Turkey's methods to detect specific groups explaining global significance. Average mark systematically increases as breakfast quality increases from an average score of 5.63 in the group with poor quality breakfast to 7.73 average score in the group with a good quality breakfast. An analysis of variance has been performed to study the statistical significance of the mean differences between both groups. The outcomes yield significant global differences between groups ( $\mathrm{p}$ value $=0.001$ ), i.e., the average mark significantly varies according to breakfast quality. When pooled quality of breakfast and mid-morning snack is analyzed, the average mark systematically increases as breakfast-snack quality increases, from an average mark of 5, 77 in the group with poor or insufficient quality up to 7.61 in the group with good quality. An analysis of variance has been used to study the statistical significance between the mean differences between groups. The outcome was that there exist global significant differences between groups ( $\mathrm{p}$ value $=0.0004$ ), i.e. the average mark significantly varies according to pooled breakfast-snack quality. Besides, we have analyzed the issue of the relative contribution of the snack quality to a determined breakfast quality. For that purpose, average marks for each combination of "breakfast quality" and "breakfast + snack quality". Thus, in the group of poor breakfast quality, those children remaining with poor or insufficient breakfast + snack quality have an average mark of 5.55, where-as those upgrading to "improvable quality" (just one child) have an average mark of 6.10. The students having an insufficient quality breakfast obtained an average mark of 5.91 if they remained with an insufficient or poor quality, and 6.30 if they upgraded to Improvable" quality, and 8.00 if they upgraded to good quality. Students having an "improvable" quality breakfast obtained an average mark of 6.82 if they remained at the same quality level and 6.96 if they upgraded to good quality.

The results showed the relationship between breakfast quality and marks: 1 . the average mark increases as breakfast quality increases (descriptive level). 2. The average mark significantly increases when breakfast quality is upgraded from poor or insufficient to good (inferential level). Relationship between pooled breakfast and mid-morning snack quality and marks: 3 . the average mark increases as pooled breakfast and snack quality increases (descriptive level). 4. the average mark significantly increases when pooled breakfast and snack quality is upgraded from poor, insufficient, or improvable to good (inferential level). Specific contribution of mid-morning snack: 5. for a given breakfast quality, mean mark increases as pooled breakfast and snack quality increases (descriptive level).

\section{Design and methodology}

\subsection{Population of the study}

The population of the study consisted of all seventh and eighth grade students in Irbid the first Directorate of Education which they form about 12320 (6630 female and 5690 male students) distributed in (63) schools during the academic year 2013/2014. 


\subsection{Sample of the study}

The sample of the study was selected by random sampling technique. It consisted of (234) students, (115) male and (119) female students at Fatima Bent Al Yaman school for girls and Khaled Ben Al Walid school for boys in Irbid the first Directorate of Education. This sample was used to measure the effectiveness health education intervention about

Breakfast for parents and whether it leads to improvement in students 'breakfast intake and their academic achievements and was distributed into two sections in each school. A control group and experimental group from third and fourth grade in each school.

\subsection{Design of the study}

The participants of the study were divided into two groups, experimental and control. The participants of the experimental group were those whose parents were exposed to health education intervention about breakfast which supposed to lead to improvement in students' breakfast intake and their academic achievements, while the participants of the control group were students whose parents were not exposed to health education intervention about breakfast and its importance in improving students' breakfast intake and their academic achievements. A pre-test was given before setting the parents in the health education intervention about breakfast which may lead to improvement in students' breakfast intake and their academic achievements, to make sure that the students are equivalent and the same test was administered as a post-test after applying the program to see whether engaging parents in this program had any influence on students achievement.

\subsection{Instrument of the study}

The researcher measured the effectiveness of health education intervention about breakfast for parents and whether it leads to improvement in students' breakfast intake and their academic achievement, and then the researcher designed a test based on the instructional material of third and fourth text books of English, Math, Science and Arabic, and collected the data. Validity and reliability were ensured. The subjects in both groups took a pretest to determine their actual level before starting the experiment, and the same test was administered as a post-test at the end of the experiment to assess students' performance. The time interval between the pre-test and the post-test was (12) weeks; a period long enough to minimize the effect of the pre-test on the results and conclusions of the experiment.

\subsection{Reliability of the instrument}

To ensure the test reliability, the researcher followed test/retest technique. The researcher applied it to a pilot sample of (25) children who were excluded from the study with a two-week period between the test and the re-test. The reliability of the test was calculated using correlation coefficient and it was 0.89 which is appropriate for conducting such a study.

\subsection{Validity of the instrument}

The researcher designed a math test taking into consideration the instructional material. The researcher validated the instrument by submitting it to a jury of three supervisors of math working at Irbid the first Directorate of Education, and two teachers of math. The researcher followed the recommendations of the referees and made amendments accordingly.

\subsection{Instructional material}

The instructional material was third and fourth grade text books of English, Math, Science, and Arabic, which includes several topics that needs critical thinking and concentration.

\subsection{Procedures of the study}

The participants of the study were divided into two groups, experimental and control: The participants of the experimental group were those students whose parents were exposed to health education intervention about breakfast which may lead to improvement in students' breakfast intake, while the participants of the control group those whose parents weren't exposed to health education intervention about breakfast. Here the researcher tried to judge whether taking the breakfast really affect students comprehension.

\subsection{Statistical analyses}

To answer the study questions, descriptive methods (means and standard deviation) were used for pre and post tests for English, Math, Science, and Arabic tests for both the experimental and control groups.

Differences statistical method (T-test) was used to make a comparison between the control and the experimental groups.

\section{Findings of the study}

The purpose of this study is to examine whether the health education intervention about breakfast for parents leads to improvement in students' breakfast intake and their academic achievements, it also aims at investigating the effect of students' gender and class on their performance.

The researcher followed the equivalent pre /posttest two group designs. Therefore, the means, standard deviations and Two-Way ANOVA analysis of variance were used to analyze data. The results will be displayed based on the questions of the research.

To determine if there is a statistically significant difference between the groups, a t-test for independent samples was conducted table 1 shows the results.

Table 1: Means and Standard Deviations of the Achievement of Groups on the Pretest.

\begin{tabular}{llllllll}
\hline & GROUP & $\mathrm{N}$ & Mean & $\begin{array}{l}\text { Std. Devia- } \\
\text { tion }\end{array}$ & $\mathrm{t}$ & $\mathrm{df}$ & $\begin{array}{l}\text { Sig. (2- } \\
\text { tailed) }\end{array}$ \\
\hline Pre & $\begin{array}{l}\text { Experimental } \\
\text { Control }\end{array}$ & 117 & 61.49 & 9.693 & .944 & 92 & .348 \\
\hline
\end{tabular}

Table 1 indicates that the difference between the experimental group whose parents were exposed to health education intervention about breakfast and control groups whose parents weren't exposed to health education intervention about breakfast is not statistically significant at $\alpha=0.05$, the mean of the experimental group was (61.49) while the mean of the control group was (59.89) which are nearly the same. Thus, since the difference was not significant, the two groups were assumed equivalent and the sample was divided into two groups, an experimental and a control group. The experimental group whose parents were exposed to health education intervention about breakfast consisted of (117) students while the control group consisted of (117) students also.

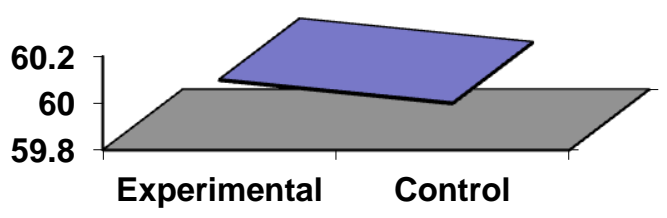

Fig. 1: Mean and Standard Deviations of the Performance of the Control and Experimental Groups on the Pretest

To answer the first question about the effect of taking breakfast on achievement: Are there any statistically significant differences in students' achievement due to the health education intervention about breakfast for parents? a post test was conducted and table 2 show the results. 
Table 2: Mean and Standard Deviations of the Performance of the Control and Experimental Groups on the Posttest

\begin{tabular}{llllllll}
\hline & GROUP & $\mathrm{N}$ & Mean & $\begin{array}{l}\text { Std. Devi- } \\
\text { ation }\end{array}$ & $\mathrm{t}$ & $\mathrm{df}$ & $\begin{array}{l}\text { Sig. (2- } \\
\text { tailed) }\end{array}$ \\
\hline Post & $\begin{array}{l}\text { Experimental } \\
\text { Control }\end{array}$ & 117 & 80.09 & 7.235 & 3.428 & 92 & .001 \\
& 117 & 72.66 & 12.970 & & & \\
\hline
\end{tabular}

Table 2 shows that there is a statistically significant difference at $\alpha=0.05$ between the achievement of the experimental group and that of the control group on the posttest in favor of the experimental group whose parents were exposed to health education intervention about breakfast. This difference indicates that having good nutrition had a positive effect on students' achievement in the exams. The mean score for the experimental group on the posttest was (80.09) while that of the control group was (72.66).

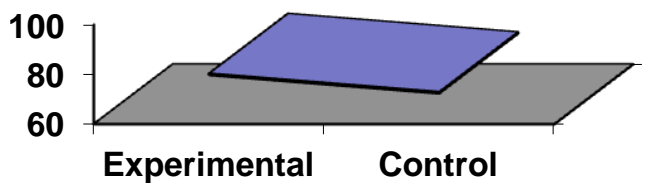

Fig. 2: Mean and Standard Deviations of the Performance of the Control and Experimental Groups on the Posttest According To Group Variable.

To answer the second question about the effect of class on performance: Are there any statistically significant differences in students' achievement due to their class (third grade, fourth grade)? A post test was conducted and table 3 shows the results.

Table 3: Mean and Standard Deviations of the Performance of the Control and Experimental Groups on the Posttest According To Class Variable

\begin{tabular}{|c|c|c|c|c|c|c|c|}
\hline & GRADE & $\mathrm{N}$ & Mean & $\begin{array}{l}\text { Std. } \\
\text { Deviation }\end{array}$ & $\mathrm{t}$ & $\mathrm{df}$ & $\begin{array}{l}\text { Sig. (2- } \\
\text { tailed) }\end{array}$ \\
\hline \multirow[t]{2}{*}{ Post } & $\begin{array}{l}3^{\text {th }} \\
\text { grade }\end{array}$ & 116 & 73.02 & 11.983 & -3.058 & 92 & .003 \\
\hline & $\begin{array}{l}4^{\text {th }} \\
\text { grade }\end{array}$ & 118 & 79.72 & 9.067 & & & \\
\hline
\end{tabular}

Table 3 shows that there is a statistically significant difference at $\alpha=0.05$ between the achievement of the experimental group and that of the control group on the posttest in favor of fourth grade group whose parents were exposed to health education intervention about breakfast. This difference indicates that good nutrition had a positive effect on students' achievement in all exams. The mean score for the third grade group on the posttest was (73.02) while that of the fourth grade group was (79.72).

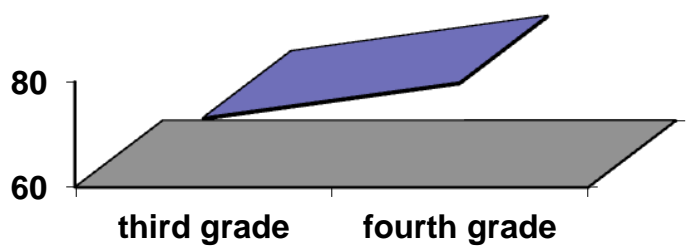

Fig. 3: Mean and Standard Deviations of the Performance of Groups on the Posttest According To Class Variable

To answer the third question about the effect of gender on performance: Are there any statistically significant differences in students' achievement due to their gender (male, female)? A post test was conducted and table 3 shows the results

Table 4: Mean and Standard Deviations of the Performance of Groups on the Posttest According To Gender Variable

\begin{tabular}{llllllll}
\hline & SEX & $\mathrm{N}$ & Mean & $\begin{array}{l}\text { Std. } \\
\text { Deviation }\end{array}$ & $\mathrm{t}$ & $\mathrm{df}$ & $\begin{array}{l}\text { Sig. (2- } \\
\text { tailed) }\end{array}$ \\
\hline Post & Male & 115 & 77.02 & 10.137 & .542 & 92 & .589 \\
& Female & 119 & 75.78 & 11.976 & .546 & 91.413 & .586 \\
\hline
\end{tabular}

Table 4 shows that there is a statistically significant difference at $\alpha=0.05$ between the achievement of the experimental group and that of the control group on the posttest in favor of male group whose parents were exposed to health education intervention about breakfast. This difference indicates that good and healthy nutrition had a positive effect on students' achievement in all exams. The mean score for the male group on the posttest was (77.02) while that of the female group was (75.7).

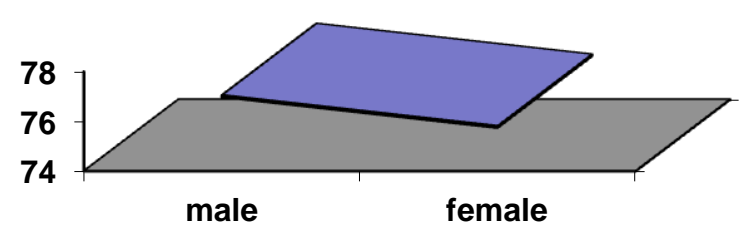

Fig. 4: Mean and Standard Deviations of the Performance of Groups on the Posttest According To Gender Variable

To answer the fourth question: Are there any statistically significant differences in students' achievement due to the interaction between group and gender? The researcher also conducted a twoway analysis of variance to analyze the posttest achievement scores of the two groups. Table 5 shows the results.

Table 5: Summary of the Two-Way Analysis of Variance of the Achievement of the Control and the Experimental Groups

\begin{tabular}{llllll}
\hline Source & $\begin{array}{l}\text { Type III } \\
\text { Sum of } \\
\text { Squares }\end{array}$ & df & $\begin{array}{l}\text { Mean } \\
\text { Square }\end{array}$ & F & Sig. \\
\hline GROUP & 1251.254 & 1 & 1251.254 & 11.265 & .001 \\
SEX & 28.014 & 1 & 28.014 & .252 & .617 \\
GROUP $*$ & 122.043 & 1 & 122.043 & 1.099 & .297 \\
SEX & 9996.367 & 90 & 111.071 & & \\
$\begin{array}{l}\text { Error } \\
\begin{array}{l}\text { Corrected } \\
\text { Total }\end{array}\end{array}$ & 11441.968 & 93 & & & \\
\hline
\end{tabular}

Table 5 shows that there is a statistically significant difference between the experimental group and the control group on the post test, the experimental means was significantly better than that of the control group. However, the information indicates that there was no significant difference attributed to the interaction between the treatment and gender.

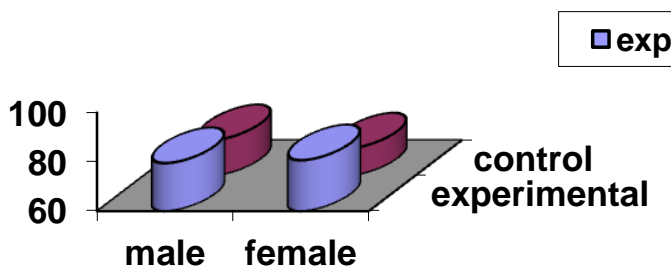

Fig. 5: Two-Way Analysis of Variance of the Achievement of the Control and the Experimental Groups

\section{Discussion}

The researcher believes that the difference in the students' performance was attributed to having a healthy breakfast by students. The experimental group subjects' performance was improved in a period of 12 weeks. The improvement achieved by the experimental group subjects, however, was statistically significant. By comparing the results achieved by the two groups, the researcher reached the conclusion that the improvement achieved by the experimental group may have been attributed to good nutrition for third and fourth grade students by exposing them to a healthy breakfast daily as a result of engaging their parents in health education intervention about breakfast.

The result of this study agreed with many other studies such as $\mathrm{Ni}$ et al (2010) who suggested in their study that regular breakfast 
consumption can improve academic performance. Another study that congruence with this study's results is Cheng et al (2008) study which showed that breakfast skipping was associated with lack of perceived parental emphasis on breakfast.

Herro \& Fillat (2006) in their study showed that there is a relationship between breakfast quality and marks which is congruence with this study.

\section{Conclusion}

In conclusion, as a treatment designed to improve the performance of students in schools by asking them have their breakfast before they come to school, having a healthy breakfast prove to have a strong effect on students learning in general and in English, Math, Science and Arabic in particular.

As a result of this experience, the researcher concluded that students were more engaged in learning when they have a good health

\section{References}

[1] Acham, H.; Kikafunda, J.; Malde, M.; Oldewage-T. , Wilna H.; and Egal, A. (2012). Breakfast, midday meals and academic achievement in rural primary schools in Uganda: implications for education and school health policy .Food \& Nutrition Research.2012, Vol. 56, p1-12. 12p. 1 Diagram, 5 Charts. DOI: 10.3402/fnr.v56i0.11217. , Database: Academic Search Complete http://dx.doi.org/10.3402/fnr.v56i0.11217.

[2] Basch, C. (2011) Breakfast and the Achievement Gap among Urban Minority Youth. Journal of School Health. Oct2011, Vol. 81 Issue 10, p635-640. http://dx.doi.org/10.1111/j.1746-1561.2011.00638.x.

[3] Cheng, T.; Tse, L.; Tak-Sun, Y. and Griffiths, S. (2008) Children's Perceptions of Parental Attitude Affecting Breakfast Skipping in Primary Sixth-Grade Students. Journal of School Health. Apr2008, Vol. 78 Issue 4, p203-208. 6p. 3 Charts, 1 Graph.

[4] Dahl, G.; and Lochner, L. (2010) the impact of family income on child achievement: Evidence from the earned income tax credit. Working paper, 2010.

[5] Florence, M.; Asbridge,M.; and P.J. Veugelers (2008). Diet quality and academic performance. Journal of School Health, 78(4):209-15, 2008. http://dx.doi.org/10.1111/j.1746-1561.2008.00288.x.

[6] Gleason, P.; and Suitor, C (2003) Eating at school: How the national school lunch program affects children's diets, American Journal of $\begin{array}{lll}\text { Agricultural } & \text { Economics, } & \text { 85:1047-1061, }\end{array}$ http://dx.doi.org/10.1111/1467-8276.00507.

[7] Herrero, L. \& Fillat, B. (2006) conducted a study entitled "A study on breakfast and school performance in a group of adolescents" Nutrición Hospitalaria [Nutr Hosp] 2006 May-Jun; Vol. 21 (3), pp. 346-52.

[8] Kawafha M.M.(2013).Impact of Skipping Breakfast on Various Educational and Overall Academic Achievements of Primary School Children in Northern of Jordan, Australian Journal of Basic and Applied Sciences, 7(7): 155-160.

[9] Kleinman,R.; Hall, S. and Green, H (2002). Diet, breakfast and academic performance in children, Ann Nutr Metab, 46(1):S24-S30, 2002. http://dx.doi.org/10.1159/000066399.

[10]Leos-Urbel, J.; Schwartz, A.; Weinstein, M.; and Corcoran, S. (2013) not just for poor kids: The impact of universal free school breakfast on meal participation and student outcomes. Economics of Education Review. Oct2013, Vol. 36, p88-107. 20p.

[11]Murphy, J. M., \& Pagano, M. (2001). Effects of a universally free, inclassroom school breakfast program, final report from the third year of the Maryland Meals for Achievement Evaluation (p 7). Boston, MA: Massachusetts General Hospital.

[12]Ni, M.; Turley, M.; Gorton, D.; Jiang, Y.; Michie, J.; Maddison, R. and Hattie, J. (2010) Effects of a free school breakfast program on school attendance, achievement, psychosocial function, and nutrition: a stepped wedge cluster randomized trial. BMC Public Health 2010 Nov 29; Vol. 10, pp. 738. Date of Electronic Publication: 2010 Nov 29.

[13]PR Newswire (2013) Healthy Students Are Better Students: New Report Illustrates "The Wellness Impact" Of Good Nutrition and Physical Activity on Improving Academic Achievement. PR Newswire US. 03/04/2013. 